\title{
Model latihan core stability cabang olahraga renang gaya kupu-kupu untuk usia 9-10 tahun
}

\author{
Vian Octrialinanggih Pradana ${ }^{1}$, Iwan Hermawan ${ }^{\mathbf{1}}$, Ika Novitaria Marani ${ }^{1}$ \\ ${ }^{1}$ Program Studi Pendidikan Olahraga, Program Pascasarjana, Universitas Negeri Jakarta. \\ Jalan Rawamangun Muka, Rawamangun, Jakarta 13220, Indonesia. \\ * Corresponding Author. Email: voctrialin@gmail.com \\ Received: 6 June 2018; Revised: 25 July 2018; Accepted: 6 August 2018
}

\begin{abstract}
Abstrak
Penelitian ini bertujuan menghasilkan produk model latihan core stability menggunakan stability ball cabang olahraga renang gaya kupu-kupu usia 9-10 tahun. Penelitian \& Pengembangan ini menggunakan pendekatan Borg dan Gall. Subjek yang digunakan 20 atlet untuk uji coba kelompok kecil, 60 atlet untuk uji coba kelompok besar, dan 30 atlet untuk uji efektifitas produk. Model latihan core stability divalidasi ahli kepelatihan kondisi fisik dan ahli olahraga renang. Hasil uji coba kelompok kecil, model latihan core stability mendapat persentase rata-rata 82,20\%. Hasil uji coba kelompok besar, model latihan core stability mendapat persentase rata-rata 79,60\%. Uji efektivitas produk menggunakan tes kecepatan renang 50 meter gaya kupu-kupu dengan rancangan pretest-posttest control group design. Dari hasil selisih pretest-posttest kelompok eksperimen dan kontrol diperoleh harga $t_{\text {hitung }}=7,776$ dengan signifikansi 0,000 . Didapatkan $\mathrm{t}_{\text {tabel }}$ dari $\mathrm{db}=58$ dari taraf signifikansi 5\% adalah 1,671. Jadi nilai $t_{\text {hitung }}>\mathrm{t}_{\text {tabel }}(7,776>1,671)$ dan sig. $(2$ tailed $)$ atau $p$-value $=0,000<0,05$. Sehingga disimpulkan terdapat efektifitas hasil kecepatan renang gaya kupu-kupu atlet renang usia 9-10 tahun yang diberikan latihan core stability menggunakan stability ball.
\end{abstract}

Kata Kunci: core stability, renang, gaya kupu-kupu

\section{Core stability exercise model in butterfly swimming for 9-10 years old children}

\begin{abstract}
This research aims to produce the model of core stability training model using stability ball in butterfly swimming for 9-10 years old. This Research \& Development uses the Borg and Gall approach. Subjects used 20 athletes for small group trials, 60 athletes for large group trials, and 30 athletes to test product effectiveness. The core stability training model is validated by physical fitness experts and swimming sport experts. Small group trial results, core stability training model got an average percentage of $82.20 \%$. The results of large group trials, core stability training model got an average percentage of $79.60 \%$. Product effectiveness test using 50 meter butterfly swimming speed test with pretest-posttest control group design. From the result of the difference beetwen the pretest-posttest experiment and control group obtained tcount $=7,776$ with significance 0,000. Obtained ttable from $\mathrm{db}$ $=58$ from $5 \%$ significance level is 1,671. So tcount > ttable $(7,776>1.671)$ and sig. $(2$ tailed) or $p$ value $=0.000<0.05$. So concluded there is effectiveness of swimming pool speed butterfly swimming athletes aged 9-10 years who are given core stability training using stability ball.
\end{abstract}

Keywords: core stability, swimming, butterfly

How to Cite: Pradana, V., Hermawan, I., \& Marani, I. (2018). Model latihan core stability cabang olahraga renang gaya kupu-kupu untuk usia 9-10 tahun. Jurnal Keolahragaan, 6(1), 60-68. doi:http://dx.doi.org/10.21831/jk.v6i1.19951

http://dx.doi.org/10.21831/jk.v6i1.19951 


\section{PENDAHULUAN}

Renang sebagai olahraga prestasi menunjukan proses perkembangan cukup pesat, hampir di setiap daerah di Indonesia mempunyai klubklub renang yang berusaha untuk mengembangkan dan membina olahraga renang sebagai olahraga prestasi. Di dalam cabang olahraga renang terdapat empat gaya renang yang sering diperlombakan baik dalam tingkat regional, nasional maupun internasional yaitu gaya punggung, gaya bebas, gaya dada, dan gaya kupu-kupu.

Renang gaya kupu-kupu adalah gerakan renang yang simetris dimana gerakan lengan digerakan secara bersama-sama dan tungkai bawah juga digerakan bersamaan (Seifert, Delignieres, Boulesteix, \& Chollet, 2007). Sehingga tubuh bergerak bergelombang ke atas dan ke bawah (Riewald \& Rodeo, 2015). Rangkaian gerakan renang tersebut yang akan mempengaruhi stabilitas atlet saat berenang. Stabilitas berbanding lurus dengan luas bidang tumpuannya (Hidayat, 2003). Bidang tumpu perenang adalah air yang keadaannya labil serta dipengaruhi oleh lingkungan berupa ombak dan angin. Sehingga rangkaian gerakan ini akan sulit dilakukan jika tidak memiliki stabilitas tubuh yang baik.

Mempertahankan stabilitas saat berenang gaya kupu-kupu bukan hal yang mudah karena menurut hukum kesetimbangan ke I "Tubuh selalu dalam keadaan seimbang selama proyeksi dari titik berat badan tersebut jatuh dalam bidang tumpuan" (Hidayat, 2003). Sedangkan saat berenang bidang tumpuanya adalah air yang keadaannya labil sehingga akan mengalami kesulitan-kesulitan saat melakukan gerakan seperti, melakukan gerakan dolphin kick yang tidak dilakukan secara maksimal dan simultan serta gerakan kaki yang tidak dapat mempertahankan posisi kaki rapat. Hal ini menyebabkan kecepatan luncuran yang dihasilkan akan kurang maksimal.

Berenang yang cepat tergantung pada kemampuan atlet untuk menghasilkan dorongan dengan tungkai dan lengan yang mencoba meminimalkan hambatan yang dialami saat berenang secara simultan. Dalam berenang gaya kupu-kupu terdapat komponen-komponen yang penting dimiliki agar dapat berenang gaya kupukupu dengan baik yaitu: Posisi tubuh, tendangan kaki, teknik nafas, penggunaan otot inti atau pusat tubuh dan kestabilan tubuh (Montgomery \& Chambers, 2009). Kestabilan berperan dalam menjaga, mepertahankan, dan mengatur posisi tubuh agar stabil dan seimbang yang dilakukan secara efektif dalam air. Oleh karena itu kestabilan tubuh mempengaruhi keseimbangan atlet dalam berenang. Kestabilan yang baik dalam berenang ditunjukan dengan gerakan streamline di sepanjang permukaan air saat berenang. Menstabilkan posisi tubuh tetap streamline saat berenang merupakan salah satu konsep dari penggunaan otot inti tubuh (core) (McLeod, 2010). Artinya dalam hal ini posisi tubuh tergantung dari pengkondisian otot inti pada batang tubuh.

Otot inti yang dikondisikan dengan baik dapat menghasilkan keseimbangan dan kestabilan atlet saat berenang (Lynn, 2007). Otot inti merupakan pusat keseimbangan seseorang (center of gravity) pada saat berenang (Miller \& Herkimer, 2012). Sehingga ketidakstabilan atlet saat berenang dapat dilihat dari ketidak teraturan gerakan yang dilakukannya. Hal ini disebabkan atlet belum mampu mengatur posisi tubuhnya saat berenang. Dikarenakan atlet belum memaksimalkan kemampuan pada otot intinya.

Permasalahan ini dapat dibantu dengan latihan core stability. "Core stability is important for providing a stable base for the application of power throught the limbs and enabling a smooth synergy between upper and lower body movemet" (Collins, 2009). Hal ini menunjukkan bahwa core stability dapat meningkatkan stabilitas dan mengurangi beban pada tubuh yang bisa menyebabkan ketidak-seimbangan otot atau cedera, dan otot-otot inti juga berfungsi sebagai penopang punggung, dapat memberikan stabilisasi dan membantu menghasilkan daya ledak selama gerakan yang dilakukan. Sehingga pentingnya core stability dalam semua aktivitas olahraga (Kibler, Press, \& Sciascia, 2006). Hal ini dikarenakan core stability mampu meningkatkan fungsi otot inti pada kestabilan tubuh. Sehingga hal yang perlu diperhatikan terkait dengan pembinaan atlet renang yaitu latihan tidak hanya dilakukan di air tetapi juga di darat (dry-land). Latihan di darat dapat meningkatkan kemampuan gaya pendo-rong di dalam air (Popovici \& Suciu, 2013). Oleh karena itu, latihan di darat perlu diberikan untuk pembentukan performa dan komponen fisik yang baik.

Latihan darat (dry-land) akan mempengaruhi kondisi fisik dan performa atlet (Aspenes, Kjendlie, Hoff, \& Helgerud, 2009). Latihan kondisi fisik memegang peranan penting dalam hal pembinaan untuk peningkatan mutu prestasi atlet. Latihan fisik mampu meningkatkan 
kekuatan otot, dimana akan terjadi kontraksi antara seluruh komponen otot besar dan otot kecil sehingga terjadi koordinasi antara kedua komponen otot tersebut. Salah satu cara untuk melatih otot-otot kecil yaitu dengan mengkontraksikan otot-otot kecil tersebut atau dengan latihan stabilisasi tubuh (Karter, 2009). Oleh karena itu, diperlukanlah penyusunan program latihan guna meningkatkan potensi dalam rangka mencapai hasil yang maksimal (Lumintuarso, 2013).

Sebelum penyusunan program latihan dan menyajikan materi latihan, hal yang harus diperhatikan khususnya untuk materi latihan penguatan otot core pada atlet usia 9-10 tahun ialah latihan core stability. Latihan ini untuk mengatur posisi badan dan gerak badan agar terkontrol dengan tujuan untuk meningkatkan keseimbangan dan kestabilan yang disesuaikan dalam gerak renang gaya kupu-kupu. Kestabilan yang baik juga akan membentuk pondasi awal untuk mempermudah latihan-latihan fisik ditahap-tahap selanjutnya ketika ingin membangun per-forma atlet yang lebih berkualitas. Oleh karena itu disarankan atlet untuk dilatih mulai dari usia 9-10 tahun. Hal ini didukung oleh Lang \& Light (2010) yang menyatakan bahwa pada usia 8-11 tahun (perempuan) dan 9-12 tahun (laki-laki) merupakan usia dimana kemampuan keterampilan gerak dasar harus dikembangkan karena pada usia tersebut merupakan masa perkembangan belajar gerak yang cepat. Jika masa ini terlewatkan, maka akan kehilangan kesempatan untuk meningkatkan potensi untuk menjadi atlet.

Latihan core stability sangatlah berperan penting dalam meningkatkan keseimbangan yang dapat mempertahankan stabilitas posisi tubuh dalam kondisi dinamis saat berenang. Latihan core stability sangat baik untuk mening-katkan kestabilan tubuh (Akuthota, Ferreiro, Moore, \& Fredericson, 2008). Oleh karena itu jika seorang perenang memiliki stabilitas tubuh yang baik pada saat berenang akan memper-mudah melakukan rangkaian gerakan renang gaya kupukupu dan meminimalisir hambatan di air. Sehingga akan menghasilkan kecepatan luncuran ke depan yang lebih maksimal. Latihan untuk meningkatkan core stability ini dapat menggunakan media stability ball.

Stability ball digunakan untuk membantu latihan keseimbangan, kelentukan dan kekuatan otot inti atau core. Latihan core stability dengan menggunakan stability ball dapat membantu dalam pengembangan stabilitas otot inti dan aktivasi otot inti (Srivastav, Nayak, Nair, Sherpa,
\& Dsouza, 2016). Bentuk stability ball memiliki keadaan yang tidak stabil sehingga jika digunakan akan meningkatkan aktivitas otot penstabil maka akan memperbaiki dan meningkatkan keseimbangan (Bompa \& Buzzichelli, 2015). Alat ini sangat cocok untuk diberikan kepada atlet renang usia 9-10 tahun dikarenakan alat ini tidak memberikan beban lebih melainkan dengan berat badan tubuh itu sendiri. Selain itu alat ini juga sangat mudah digunakan dimana saja (outdoor atau indoor), menarik, aman, dan dapat dilakukan oleh semua jenjang usia, laki-laki dan perempuan. Alat ini dirancang khusus untuk menciptakan ketidakstabilan sehingga dengan ketidakstabilan ini tubuh dilatih agar dapat mempertahankan posisi tetap stabil se-hingga menciptakan keseimbangan dan stabilitas secara alami.

Tujuan yang diharapkan dalam penelitian ini adalah memberikan model latihan fisik untuk peningkatan keseimbangan dan stabilitas otot inti dengan latihan core stability menggunakan stability ball. Sehingga hasil dari latihan tersebut dapat meningkatkan kecepatan dalam renang gaya kupu-kupu. Berdasarkan pembahasan di atas inilah peneliti ingin melakukan penelitian tentang "Model latihan core stability dengan menggunakan stability ball pada cabang olahraga renang gaya kupu-kupu untuk usia 9-10 tahun".

\section{METODE}

Penelitian ini menggunakan pendekatan penelitian dan pengembangan (Research and development atau R\&D) penelitian ini mengadopsi dari tahapan pengembangan yang dikemukakan oleh (Borg \& Gall, 1983). Langkahlangkah rancangan tersebut ialah sebagai berikut: (1) penelitian dan pengumpulan data informasi, (2) perencanaan, (3) mengembangkan bentuk model, (4) validasi ahli, (5) merevisi hasil uji dari para ahli, (6) uji coba pada kelom-pok kecil, (7) penyempurnaan produk hasil uji coba lapangan, (8) uji pelaksanaan lapangan pada kelompok yang lebih besar, (9) penyem-purnaan produk akhir, Penyempurnaan didasar-kan masukan dari uji coba pelaksanaan lapang-an, (10) diseminasi dan implimentasi.

Subjek penelitian adalah atlet renang usia 9-10 tahun di masing-masing klub renang. Daerah kajian adalah DKI Jakarta dan Tegal Jawa tengah serta dipilih dengan menggunakan metode purposive random sampling. Uji coba skala kecil dilakukan di klub renang Arcadia Jakarta berjumlah 20 atlet usia 9-10 tahun. Uji coba lapangan 
Jurnal Keolahragaan 6 (1), 2018 - 63

Vian Octrialinanggih Pradana, Iwan Hermawan, Ika Novitaria Marani

skala besar dilakukan di 4 klub renang yaitu: klub renang Phyramid Jakarta berjumlah 15 atlet usia 9-10 tahun, klub renang Indonesia Star Aquatik berjumlah 15 atlet usia 9-10 tahun, klub renang Embun Pagi Jakarta berjumlah 15 atlet usia 9-10 tahun, dan klub renang Binataruna Jakarta berjumlah 15 atlet usia 9-10 tahun.

\section{Instrumen Pengumpulan Data}

Instrumen yang digunakan dalam pengembangan model latihan core stability menggunakan stability ball adalah dengan menggunakan wawancara, kuesioner dan tes kecepatan renang 50 meter gaya kupu-kupu. Wawancara dalam penelitian ini digunakan untuk analisis kebutuhan yaitu mendapatkan data informasi pendapat pelatih terhadap model latihan yang pernah atau sedang mereka gunakan dan model latihan seperti apa yang mereka inginkan. Kuesioner digunakan untuk evaluasi ahli dan hasil penilaian atlet (dalam uji coba kelompok kecil dan uji coba kelompok besar). Instrumen tes kecepatan 50 meter renang gaya kupu-kupu digunakan untuk mendapatkan data efektifitas implementasi model latihan core stability menggunakan stability ball melalui pretest dan posttest.

\section{Teknik Analisis Data}

Teknik analisis data yang digunakan dalam penelitian pengembangan latihan ini adalah teknik analisis kualitatif dan teknik analisis kuantitatif. Teknik analisis kualitatif di-gunakan untuk menganalisis data yang diperoleh dari para ahli berupa saran dan masukan menge-nai model yang dikembangkan. Model yang dikembangkan dianggap layak untuk diujicoba-kan pada skala kecil maupun besar apabila para ahli telah menentukan model-model latihan yang sesuai dengan karakteristik latihan yang ingin dicapai. Sedangkan teknik analisis kuantitatif digunakan untuk mengelola data yang didapat dari hasil uji coba kelompok kecil dan uji coba lapangan kelompok besar serta uji efektivitas model.

Teknik analisis data kuantitatif yang digunakan adalah teknik analisis deskriptif kuantitatif dengan persentase (Sudjana, 2010). Teknik ini digunakan untuk menganalisa data kuantitatif yang diperoleh dari hasil penyebaran angket evaluasi dari atlet renang usia 9-10 tahun mengenai hasil produk yang dikembangkan.

Untuk menentukan kesimpulan yang telah tercapai maka ditetapkan kriteria norma kategori. Norma kategorisasi yang digunakan sesuai ketentuan (Wahjoedi, 2000) sebagaimana pada Tabel 1.

Tabel 1. Norma Kategorisasi

\begin{tabular}{cc}
\hline Skala Evaluasi & Kategori \\
\hline $85-100$ & Sangat Baik \\
$70-84$ & Baik \\
$55-69$ & Sedang \\
$40-54$ & Kurang \\
$0-39$ & Sangat Kurang \\
\hline
\end{tabular}

Dalam penelitian ini norma kategorisasi sangat kurang dan kurang diasumsikan sebagai tidak sesuai/tidak efektif, sedang kategori sedang diasumsikan sesuai/cukup efektif, dan sangat baik dan baik sebagai sesuai/efektif.

\section{Desain Uji Coba}

Pada uji coba model yang telah dikembangkan dengan mengimplementasikan ke dalam latihan yang sesungguhnya. Pelatih akan memberikan penjelasan mengenai model latihan yang dikembangkan untuk dilaksanakan dalam latihan sesungguhnya. Desain penelitian yang digunakan dalam penelitian ini ialah pretestposttest control group design. Dalam desain ini terdapat dua kelompok yang dipilih secara random, kemudian sebelumnya diberi pretest untuk mengetahui keadaan awal antara kelompok eksperimen dan kelompok control (Sugiyono, 2015).

Setelah hasil dari pretest dua kelompok tersebut diketahui, maka pada kelas eksperimen diberikan perlakuan $(\mathrm{X})$, sedangkan pada kelas kontrol tidak diberikan perlakuan (X). Selanjutnya setelah diberikan treatment pada salah satu kelompok sampel (kelompok eksperimen) dilanjutkan dengan pemberian posttest pada kedua kelompok sampel yang digunakan. Pengaruh dari treatment disimbolkan dengan (O2-O1)-(O4-O3) dan selanjutnya untuk melihat penga-ruh treatment berdasarkan signifikasinya adalah dengan menggunakan uji statistik.

Apabila terdapat perbedaan yang signifikan antara kelompok kontrol dan kelompok ekperimen, maka treatment yang diberikan berpengaruh secara signifikan. Untuk lebih jelasnya tentang desain penelitian yang digunakan dalam penelitian ini, dapat dilihat pada Tabel 2.

Tabel 2. Desain Penelitian Pretest-Posttest

Control Group Design (Sugiyono, 2015)

\begin{tabular}{cccc}
\hline Subjek & Pretest & P & Posttest \\
\hline $\mathbf{R}$ & $\mathbf{O}_{1}$ & $\mathbf{X}$ & $\mathbf{O}_{2}$ \\
$\mathrm{R}$ & $\mathrm{O}_{3}$ & - & $\mathrm{O}_{4}$ \\
\hline
\end{tabular}

$\mathrm{R}$ = kelompok dipilih secara random 
$\mathrm{X}$ = perlakuan atau sesuatu yang diujikan

$\mathrm{O} 1=$ hasil pretest kelas eksperimen

$\mathrm{O} 3=$ hasil pretest kelas kontrol

$\mathrm{O} 2$ = hasil posttest kelas eksperimen

$\mathrm{O} 4=$ hasil posttest kelas kontrol

\section{HASIL DAN PEMBAHASAN}

Tahapan pengembangan yang dikemukakan oleh (Borg \& Gall, 1983). Langkah-langkah rancangan tersebut ialah sebagai berikut: (1) penelitian dan pengumpulan data informasi, (2) perencanaan, (3) mengembangkan bentuk model, (4) validasi ahli, (5) merevisi hasil uji dari para ahli, (6) uji coba pada kelompok kecil, (7) penyempurnaan produk hasil uji coba lapangan, (8) uji pelaksanaan lapangan pada kelompok yang lebih besar, (9) penyempurnaan produk akhir, Penyempurnaan didasarkan masukan dari uji coba pelaksanaan lapangan, (10) diseminasi dan implimentasi.

\section{Penelitian dan Pengumpulan Data Informasi}

Pengembangan model latihan core stability cabang olahraga renang gaya kupu-kupu usia 9-10 tahun yang akan dikembangkan adalah hasil dari permasalahan yang ditemukan dilapangan oleh peneliti melalui kajian penelitian yang relevan, obeservasi dan wawancara.

Kajian penelitian yang dilakukan Popovici $\&$ Suciu (2013) dengan judul "Dry land training and swimming performance in children aged 1112 years". Penelitian yang dilakukan oleh Akuthota et al. (2008) dengan judul "Core stability exercise principles". Penelitian yang dilakukan Srivastav et al. (2016) dengan judul "Swiss Ball Versus Mat Exercises for Core Activation of Transverse Abdominis in Recreational Athletes".

Dari hasil data yang telah dikumpulkan peneliti melalui wawancara dan observasi di lapangan kemudian dideskripsikan dan dianalisis sehingga hasil ini bersifat analitis dan deskriptif, dengan mengacu pada tujuan studi pendahuluan. Tabel 3 menjabarkan mengenai hasil analisis kebutuhan dan temuan lapangan yang diperoleh peneliti.

Berdasarkan hasil temuan di lapangan menunjukkan bahwa dari 3 klub renang yang diteliti semua memiliki sarana dan prasarana pendukung latihan kondisi fisik atlet renang, hanya saja masih terbatasnya media untuk latihan core stability yaitu stability ball. Latihan core stability yang diberikan kepada atlet masih dengan metode konvensional yaitu hanya menggunakan matras dan tempat yang datar.
Sehingga dibutuhkan model-model latihan core stability menggunakan stability ball untuk usia atlet 9-10 tahun yang variatif disesuaikan dengan masa perkembangan fisik atlet dan disesuaikan juga dengan karakteristik gaya renang yang dibutuhkan khususnya pada renang gaya kupukupu.

Tabel 3. Temuan Hasil Dari Tahapan

Pelaksanaan Penelitian Pengembangan

\begin{tabular}{l} 
Hasil/Temuan \\
\hline 1. Atlet renang di klub renang selain latihan di air \\
juga diberikan latihan fisik di darat (dry land) \\
untuk menigkatkan performanya saat berenang. \\
Karena yang menghambat kemampuan teknik \\
adalah terbatasnya kemampuan fisik. \\
2. Latihan fisik yang diberikan kepada atlet renang \\
usia 9-10 tahun antara 2-3 kali dalam seminggu. \\
3. Atlet renang usia 9-10 tahun diberikan latihan \\
core stability \\
4. Media yang digunakan untuk latihan core \\
stability hanya matras dan tempat yang datar. \\
5. Model-model latihan core stability yang \\
diberikan kepada atlet adalah model-model \\
latihan core stability dengan menggunakan \\
matras sebagai alas dan proses latihannya \\
dengan berat badan sendiri (on body weight). \\
Latihan core stability yang disesuaikan dengan \\
renang khususnya kebutuhan untuk renang gaya \\
kupu-kupu, variasi latihannya seperti plank dan \\
variasi-variasi latihannya masih sedikit. \\
6. Masih dibutuhkan model-model latihan kondisi \\
fisik yaitu latihan core stability menggunakan \\
stability ball untuk usia atlet 9-10 tahun dan \\
disesuaikan juga dengan karakteristik gaya \\
renang yang dibutuhkan khususnya pada renang \\
khususnya pada renang gaya kupu-kupu.
\end{tabular}

\section{Perencanaan dan Mengembangkan Bentuk Model}

Tahap-tahap penyusunan model latihan core stability menggunakan stability ball mencakup beberapa kegiatan berikut: Penyusunan draf awal model atau desain awal model, dasar penyusunan draf awal model yang digunakan adalah hasil studi pendahuluan, melalui kajian teori-teori tentang core stabiliy menggunakan stability ball, teori pengembangan model, dan kelayakan implementasinya serta desain model latihan berbasis media stability ball. Adapun model latihan fisik core stability dengan menggunakan stability ball dalam renang gaya kupukupu untuk usia 9-10 tahun yang dirancang adalah sebagai berikut:

Model draft pertama yang dikembangkan untuk latihan core stability menggunakan stability ball antara lain: Model latihan Standing 
push, model latihan Flamingo, model latihan Wings plane, model latihan Push ball in the wall, model latihan One arm push ball in wall, model latihan " $T$ " in wall 7, model latihan Roll top, model latihan Dip with ball, model latihan Dancing Horse, model latihan Dancing Duck, model latihan Seat on ball torso near knee, model latihan Dead Bug, model latihan Bow, model latihan Bridge, model latihan Sit up with leg on ball, model latihan Bridge decline, model latihan " $V$ " Straight, model latihan Legs curl, model latihan Dolphin, model latihan One wings plane, model latihan Table ball, model latihan Table ball twist, model latihan Head on ball with wings plane, model latihan Press ball, model latihan Montain climber, model latihan Superman, model latihan Starfish, model latihan Cobra, model latihan Butterfly, model latihan Scorpion, model latihan Caterpillar, model latihan Lizard, model latihan Legs drop, model latihan Sea lion, model latihan Roll the ball, model latihan Mermaid, model latihan Leg out-in, model latihan See saw, model latihan Leg raise, model latihan Dung beetle, model latihan Hip up, dan model latihan One arm push back.

\section{Validasi Ahli}

Tabel 4. Saran para Ahli

\section{Data Saran para Ahli}

1. Petunjuk pelaksanaan melakukan gerakan harus dibuat secara jelas supaya mudah untuk dipahami.

2. Gerakan latihan disesuaikan dengan kemampuan atlet dan umur atlet.

3. Gerakan latihan harus dimulai dari tingkat yang sederhana ke gerakan latihan yang kompleks.

4. Gerakan latihan harus disesuaikan dengan tujuan latihan.

5. Gerakan latihan core stability menggunakan stability ball harus disesuaikan dengan karakteristik renang gaya kupu-kupu

6. Gambar yang digunakan harus jelas.

7. Model-model latihan core stability menggunakan stability ball harus aman dilakukan oleh atlet.

Model draf divalidasi oleh ahli untuk menentukan kelayakan model latihan core stability menggunakan stability ball, 2 orang berprofesi sebagai dosen kepelatihan kondisi fisik Universitas Negeri Yogyakarta sebagai ahli latihan kondisi fisik (Dr. Ria Lumintuarso, M.Si dan Dr. Devi Tirtawirya, M.Or), 1 orang berprofesi sebagai dosen renang Universitas Negeri Jakarta sebagai ahli olahraga renang (Fajar Vidya Hartono, M.Pd), dan 1 orang berprofesi sebagai pelatih renang di klub renang Binataruna Jakarta sebagai ahli kepelatihan olahraga renang (Andi Febrianto, S.Pd).

Dari hasil uji para ahli didapatkan 33 model latihan yang layak untuk digunakan pada tahap uji coba berikutnya. Tabel 4 merupakan saran dari para ahli yang membangun untuk menyempurnakan model latihan core stability menggunakan stability ball cabang olahraga renang gaya kupu-kupu usia 9-10 tahun.

\section{Uji Coba Skala Kecil}

Jumlah butir pertanyaan untuk uji coba kelompok kecil adalah 66 pertanyaan yaitu 33 pertanyaan tentang kemudahan model latihan core stability dan 33 pertanyaan tentang kemenarikan model latihan core stability. Pada uji coba kelompok kecil menggunakan 20 atlet renang usia 9-10 tahun di klub renang Arcadia. Tabel 5 adalah analisis data dari uji coba kelompok kecil.

Tabel 5. Hasil Analisis pada Uji Coba Skala Kecil

\begin{tabular}{ccccc}
\hline \multicolumn{1}{c}{ Variabel } & $\begin{array}{c}\text { Skor } \\
\text { Hasil }\end{array}$ & $\begin{array}{c}\text { Skor } \\
\text { Max }\end{array}$ & $\%$ & Ket. \\
\hline Kemudahan & 533 & 660 & 80,76 & Baik \\
Kemenarikan & 552 & 660 & 83,20 & Baik \\
Rata-rata & & 82,20 & Baik \\
\hline
\end{tabular}

Berdasarkan Tabel 5 pada skala kecil diperoleh hasil rata-rata kemudahan dan kemenarikan $82,20 \%$, maka sesuai dengan skala evaluasi penilaian termasuk dalam kategori baik. Hasil analisis data dari uji coba skala kecil disimpulkan bahwa model latihan core stability untuk usia 910 tahun dapat dilanjutkan ke uji coba kelompok besar dengan beberapa catatan diantaranya: (1) Ukuran stability ball disesuai-kan dengan postur tubuh atlet. (2) Perbanyak jumlah matras dan stability ball agar lebih efektif.

\section{Uji Coba Skala Besar}

Jumlah butir pertanyaan untuk uji coba kelompok besar adalah 66 pertanyaan. Pada uji coba kelompok besar menggunakan 60 atlet masing-masing dari klub renang di Jakarta yaitu: Klub renang Indonesia Star Aquatik (ISA), Phyramid, Embun Pagi, Binataruna. Tabel 6 adalah analisis data yang dilakukan berdasarkan data hasil evaluasi dari uji coba kelompok besar.

Berdasarkan Tabel 6 pada uji coba skala besar diperoleh hasil rata-rata kemudahan dan kemenarikan 79,60\%, maka sesuai dengan skala evaluasi penilaian termasuk dalam kategori baik. Hasil analisis data uji coba skala besar pada atlet 
dari klub renang Indonesia Star Aquatik (ISA), Phyramid, Embun Pagi, Binataruna dapat disimpulkan bahwa model latihan core stability untuk usia 9-10 tahun dapat dijadikan produk akhir karena semua aspek dikategorikan baik.

Tabel 6. Hasil Analisis pada

Uji Coba Skala Besar

\begin{tabular}{lcccc}
\hline \multicolumn{1}{c}{ Variabel } & $\begin{array}{r}\text { Skor } \\
\text { Hasil }\end{array}$ & $\begin{array}{r}\text { Skor } \\
\text { Max }\end{array}$ & $\%$ & Ket \\
\hline Kemudahan & 1562 & 1980 & 78,89 & Baik \\
Kemenarikan & 1590 & 1980 & 80,30 & Baik \\
\multicolumn{2}{c}{ Rata-rata } & & 79,60 & Baik \\
\hline
\end{tabular}

\section{Uji Coba Efektifitas Produk}

Setelah selesai produk akhir direvisi kemudian produk latihan core stability dieksperimenkan untuk mengetahui efektivitas dari pengem-bangan produk tersebut. Uji efektivitas produk ini menggunakan rancangan pretestposttest control group design.

Uji t Pretest dan Posttest Kelompok Eksperimen

Uji t pretest dan posttest kelompok eksperimen bertujuan untuk mengetahui ada tidaknya peningkatan waktu dari hasil implementasi model. Kesimpulan penelitian dinyatakan signifikan apabila t hitung $>\mathrm{t}$ tabel pada taraf signifikansi $5 \%$ dan nilai $\mathrm{p}<0,05$. Adapun ringkasan uji t pretest dan posttest kelompok eksperimen ditunjukan pada Tabel 7.

Tabel 7. Hasil uji t pretest dan posttest kelompok eksperimen

\begin{tabular}{ccccc}
\hline $\begin{array}{c}\text { Kelompok } \\
\text { eksperimen }\end{array}$ & $\begin{array}{c}\text { Rata- } \\
\text { rata }\end{array}$ & thitung & $\mathbf{t}_{\text {tabel }}$ & $\mathbf{p}$ \\
\hline Pretest & 45,13 & 17,846 & 2,045 & 0,000 \\
\hline posttest & 42,28 & & \\
\hline
\end{tabular}

Berdasarkan Tabel 7, didapatkan rata-rata nilai pretest kelompok eksperimen sebesar 45,13 detik dan rata-rata nilai posttest sebesar 42,28 detik, sehingga mengalami peningkatan kecepatan sebesar 2,85 detik. Didapatkan juga t hitung > $\mathrm{t}$ tabel pada taraf signifikansi 5\% (17,846 $>$ $2,045)$ dan mempunyai nilai $\mathrm{p}<0,05$ yang berarti dapat disimpulkan terdapat peningkatan secara signifikan pada hasil kecepatan renang 50 meter gaya kupu-kupu kelompok eksperimen.

\section{Uji t Pretest dan Posttest Kelompok Kontrol}

Uji t pretest dan posttest kelompok kontrol bertujuan untuk mengetahui ada tidaknya peningkatan waktu yang tidak latihan core stability. Kesimpulan penelitian dinyatakan signifikan apabila $\mathrm{t}$ hitung $>\mathrm{t}$ tabel pada taraf signifikansi $5 \%$ dan nilai $\mathrm{p}<0,05$. Adapun ringkasan uji t pretest dan posttest kelompok kontrol ditunjukan pada Tabel 8.

Berdasarkan Tabel 8, didapatkan rata-rata nilai pretest kelompok kontrol sebesar 48,23 detik dan rata-rata nilai posttest sebesar 47,18 detik, sehingga mengalami peningkatan kecepatan sebesar 1,05 detik. Didapatkan juga t hitung > $\mathrm{t}$ tabel pada taraf signifikansi $5 \%(6,241>2,045)$ dan mempunyai nilai $\mathrm{p}<0,05$ yang berarti dapat disimpulkan bahwa terdapat peningkatan secara signifikan pada hasil kecepatan renang 50 meter gaya kupu-kupu kelompok kontrol.

Tabel 8. Hasil Uji T Pretest dan Posttest Kelompok Kontrol

\begin{tabular}{ccccc}
\hline $\begin{array}{c}\text { Kelompok } \\
\text { Kontrol }\end{array}$ & Rata-rata & $\mathbf{t}_{\text {hitung }}$ & $\mathbf{t}_{\text {tabel }}$ & $\mathbf{p}$ \\
\hline Pretest & 48,23 & \multirow{2}{*}{6,241} & 2,045 & 0,000 \\
\hline Posttest & 47,18 & & \\
\hline
\end{tabular}

Uji t Rata-Rata Selisih dari Pretest-Posttest Kelompok Eksperimen dan Kontrol

Selanjutnya untuk melihat efektifitas pengaruh perlakuan berdasarkan signifikasinya adalah dengan menggunakan uji perbedaan ratarata dua mean independent. Analisis independent-Sample t-test terhadap hasil selisih pretest-posttest kelompok eksperimen dan kontrol. Bertujuan untuk mengetahui ada tidaknya perbedaan yang signifikan nilai pretest-posttest pada kelompok eksperimen dan kelompok kontrol. Kesimpulan penelitian dinyatakan signifikan jika $\mathrm{t}$ hitung $>\mathrm{t}$ tabel pada taraf signifikansi $5 \%$ dan nilai $\mathrm{p}<0,05$. Adapun ringkasan uji $\mathrm{t}$ selisih pretest-posttest kelompok eksperimen dan selisih pretest-posttest kelompok kontrol ditunjukan pada Tabel 9.

Tabel 9. Hasil Uji t Rata-rata Selisih PretestPosttest Kelompok Eksperimen dan Kontrol

\begin{tabular}{ccccc}
\hline Kelompok & Rata-rata & thitung $_{\text {tabel }}$ & P \\
\cline { 1 - 2 } Eksperimen & 2,85 & \multirow{2}{*}{7,776} & \multirow{2}{*}{1,671} & 0,000 \\
\cline { 1 - 2 } Kontrol & 1,05 & & & \\
\hline
\end{tabular}

Diketahui rata-rata hasil selisih pretestposttest kecepatan renang 50 meter gaya kupukupu kelompok ekeperimen sebesar 2,85 detik dan rata-rata selisih pretest-posttest kecepatan renang 50 meter gaya kupu-kupu kelompok kontrol sebesar 1,05 detik, sehingga dapat disimpulkan bahwa atlet renang usia 9-10 tahun yang diberikan latihan core stability dengan menggunakan stability ball saat renang 50 meter gaya kupu-kupu menghasilkan peningkatan 
kecepatan lebih cepat dibandingkan dengan atlet yang tidak diberikan latihan core stability. Dari tabel tersebut diketahui t hitung sebesar 7,776 dengan signifikansi 0,000. Didapatkan t tabel dari db 58 pada taraf signifikansi 5\% adalah 1,671. Jadi nilai t hitung > t tabel $(7,776>1,671)$ dan nilai signifikansinya kurang dari $0,05(\mathrm{p}=0,000$ $<0,05)$. Maka tolak $\mathrm{H}_{0}$. Dapat disim-pulkan bahwa terdapat efektifitas hasil kecepat-an renang gaya kupu-kupu pada atlet renang usia 910 tahun yang diberikan latihan core stability dengan menggunakan stability ball.

Berdasarkan analisis tersebut, terbukti bahwa terdapat perbedaan hasil kecepatan renang gaya kupu-kupu yang signifikan antara atlet yang diberikan latihan core stability dengan atlet yang tidak diberikan latihan core stability. Hal yang menyebabkan atlet yang diberikan latihan core stability memiliki rerata kecepatan renang lebih cepat dibandingkan dengan atlet yang tidak diberikan latihan core stability dika-renakan latihan core stability sangatlah berperan penting dalam meningkatkan keseimbangan yang dapat mempertahankan stabilitas posisi tubuh dalam kondisi dinamis saat berenang.

Latihan core stability sangat baik untuk meningkatkan kestabilan tubuh (Akuthota et al., 2008). Oleh karena itu jika seorang perenang memiliki stabilitas tubuh yang baik pada saat berenang akan mempermudah melakukan rangkaian gerakan renang gaya kupu-kupu dan meminimalisir hambatan di air. Sehingga akan menghasilkan kecepatan luncuran ke depan yang lebih maksimal. Hal ini dikarenakan core stability mampu meningkatkan fungsi otot inti pada kestabilan tubuh. Sehingga hal yang perlu diperhatikan terkait dengan pembinaan atlet yaitu latihan tidak hanya dilakukan di air tetapi juga di darat (dry-land). Latihan di darat dapat meningkatkan kemampuan gaya pendorong di dalam air (Popovici \& Suciu, 2013). Oleh karena itu, latihan di darat perlu diberikan untuk pembentukan performa dan komponen fisik yang baik.

\section{SIMPULAN}

Model latihan core stability menggunakan stability ball secara keseluruhan dari para ahli menyatakan model yang dikembangkan termasuk layak digunakan. Model latihan core stability menggunakan stability ball dari hasil Uji coba kelompok kecil dan uji coba kelompok besar dinyatakan mudah dan menarik untuk dilakukan. Model latihan core stability menggu-nakan stability ball efektif untuk meningkatkan kecepatan renang gaya kupu-kupu atlet usia 9-10 tahun.

Selain berupa buku panduan model latihan core stability, produk penelitian dibuat dalam bentuk CD latihan core stability renang gaya kupu-kupu. Di samping itu, perlu dilaku-kan penelitian yang melibatkan subjek coba lebih besar dan cakupan tempat uji coba lapangan yang lebih luas.

\section{DAFTAR PUSTAKA}

Akuthota, V., Ferreiro, A., Moore, T., \& Fredericson, M. (2008). Core stability exercise principles. Current Sports Medicine Reports, 7(1), 39-44. https://doi.org/10.1097/01.CSMR.000030 8663.13278.69

Aspenes, S., Kjendlie, P.-L., Hoff, J., \& Helgerud, J. (2009). Combined strength and endurance training in competitive swimmers. Journal of Sports Science and Medicine , 8, 357-365. Retrieved from https://www.jssm.org/vol8/n3/7/v8n37text.php

Bompa, T., \& Buzzichelli, C. (2015). Periodization training for sports. Human kinetics.

Borg, W. R., \& Gall, M. D. (1983). Educational research: An introduction. New York: Longman.

Collins, P. (2009). Speed for sport: Build your strongest body ever with Australia's body coach. Meyer \& Meyer Verlag.

Hidayat, I. (2003). Biomekanika. Bandung: Universitas Pendidikan Indonesia.

Karter, K. (2009). Balance training: Stability workouts for core strength and a sculpted body. Ulysses Press.

Kibler, W. Ben, Press, J., \& Sciascia, A. (2006). The role of core stability in athletic function. Sports Medicine, 36(3), 189198.

Lang, M., \& Light, R. (2010). Interpreting and implementing the long term athlete development model: English swimming coaches' views on the (swimming) LTAD in practice. International Journal of Sports Science \& Coaching, 5(3), 389-402. https://doi.org/10.1260/17479541.5.3.389

Lumintuarso, R. (2013). Teori kepelatihan olahraga. Jakarta: LANKOR Kemenpora.

Lynn, A. (2007). Conditioning for swimmers: A 


\section{Jurnal Keolahragaan 6 (1), 2018 - 68}

Vian Octrialinanggih Pradana, Iwan Hermawan, Ika Novitaria Marani

guide to land-based training. Crowood press.

McLeod, I. (2010). Swimming anatomy. Human Kinetics.

Miller, I. L., \& Herkimer, J. (2012). Functional strength for triathletes: Exercises for top performance. Meyer \& Meyer Verlag.

Montgomery, J., \& Chambers, M. (2009). Mastering swimming. Human Kinetics.

Popovici, C., \& Suciu, M. A. (2013). Dry land training and swimming performance in children aged 11-12 years. Palestrica of the Third Millennium Civilization \& Sport, 14(3).

Riewald, S., \& Rodeo, S. (2015). Science of swimming faster. Human Kinetics.

Seifert, L., Delignieres, D., Boulesteix, L., \& Chollet, D. (2007). Effect of expertise on butterfly stroke coordination. Journal of
Sports Sciences, 25(2), 131-141. https://doi.org/10.1080/026404106005984 71

Srivastav, P., Nayak, N., Nair, S., Sherpa, L. B., \& Dsouza, D. (2016). Swiss ball versus mat exercises for core activation of transverse abdominis in recreational athletes. Journal of Clinical and Diagnostic Research, 10(12).

Sudjana, N. (2010). Penilaian hasil proses belajar mengajar. Bandung: PT Remaja Rosdakarya.

Sugiyono. (2015). Metode penelitian pendidikan: Pendekatan kuantitatif, kualitatif, dan $R$ \& $D$. Bandung: Alfabeta.

Wahjoedi. (2000). Tes pengukuran dalam pendidikan jasmani dan olahraga. Ujung Pandang: Badan kerjasama Perguruan Tinggi Negeri Indonesia Timur. 